\title{
CRISPR: ¿EL SUEÑO SE CONVIERTE EN PESADILLA? A PROPÓSITO DEtL POLÉMICO EXPERIMENTO GENÉTICO PARA PROTEGER A DOS NIÑAS CONTRA EL VIRUS DEL SIDA
}

\author{
CRISPR: IS THE DREAM BECOMING A NIGHTMARE? \\ A PURPOSE OF THE POLITICAL GENETIC EXPERIMENT TO PROTECT TWO \\ GIRLS AGAINST AIDS VIRUS
}

Jazmín Adrianzén Ávila* Lilia Pérez Morán ${ }^{* *}$

\section{Resumen:}

El presente artículo desarrolla una reflexión desde una perspectiva ética y jurídica acerca de CRISPR-CAS9, una prometedora y revolucionaria técnica que permite editar o corregir de forma específica y sencilla el código genético. La accesibilidad económica, sencillez y rapidez que caracterizan a esta técnica, han dado lugar a una nueva era en el campo de la ciencia, representando un gran avance en la edición genética. Sin embargo, tal parece que sus aplicaciones no han sido realizadas con cautela, pues pese a la prohibición de la edición genética en la línea germinal, esta técnica recientemente ha sido aplicada en dos fetos, dando lugar al primer nacimiento de dos niñas editadas genéticamente bajo dicha técnica, a fin de protegerlas del virus del VIH, abriendo un gran debate ético, jurídico y social. ${ }^{* * *}$

Palabras claves: Bioética, autotelia, eugenesia, autonomía científica, CRISPR, Edición genética.

\section{Abstract:}

The present article can be a reflection from an ethical and legal perspective about CRISPR-CAS9, a promising and revolutionary technique that allows editing or correcting the specific and simple form of the genetic code. The economic accessibility, simplicity and the rapidity that characterize, have given rise to a new era in science, representing a great advance in the field of genetic publishing.

Estudiante del IX ciclo de la Facultad de Derecho de la UNIFÉ, ex representante ante el Consejo Estudiantil de la Facultad de Derecho. Correo electrónico: jazminadrianzen14@gmail.com.

** Estudiante del IX ciclo de la Facultad de Derecho de la UNIFÉ. Correo electrónico: liliaximenap@gmail.com

*** El presente artículo ha sido desarrollado en el curso de Seminario de Bioética y Biojurídica, con el apoyo del Dr. Ronald Cárdenas Krenz, Magíster en Derecho Civil y Comercial, Magíster en Bioética y Biojurídica, Investigador del Instituto de Investigación Científica (IDIC) y profesor de las Facultades de Derecho de la Universidad de Lima, Universidad Femenina del Sagrado Corazón, ESAN y San Martin de Porres. 
However, there have been no limits, nor has it been published, but it has been included in the genetic edition in the germinal line, this technique has been applied in two fetuses, as the birthplace of two girls genetically engineered under this technique, in order to protect them from HIV virus, opening a great ethical, legal and social debate.

Key words: Bioethics, autotelic, eugenics, scientific autonomy, CRISPR, genetic edition.

\section{INTRODUCCIÓN}

El sueño de poder editar el código genético, incluyendo el de los humanos, ya es una realidad. La llegada de CRISPR-CAS9 ha cambiado totalmente el panorama de la edición genética, brindándonos una técnica fácil, sencilla y barata, que nos permite editar, modificar o alterar de manera específica nuestro ADN, ofreciéndonos un procedimiento casi tan sencillo como arreglar un error tipográfico.

Sin duda, la aparición de esta técnica ha significado un gran avance para la ciencia; las aplicaciones de CRISPR-CAS9 son infinitas, nos permite editar los genes de cualquier organismo, incluyendo, el de los humanos, haciendo posible modificar errores en nuestro ADN, de modo que podríamos invertir los efectos de una enfermedad o corregir alguna anomalía, entre otras aplicaciones.

Sin embargo, diversos científicos reconocidos en biomedicina han indicado que la técnica es susceptible de cometer errores, dado que si bien se caracteriza por su especificidad, esta no es absoluta y puede terminar cortando parte de nuestro ADN que no esperábamos, generando con ello mutaciones no deseadas. Este sería el motivo por el cual la técnica aún no debería ser aplicada en humanos, - al menos todavía - pero, a pesar de ello, hay algunos científicos que pasan por alto tales advertencias.

Uno de los casos más polémicos y criticados por la comunidad científica, es el del científico He Jiankui, responsable del nacimiento de las gemelas Lulu y Nana, dos pequeñas nacidas en China que fueron editadas genéticamente bajo la técnica CRISPR-CAS9, a fin de protegerlas del virus del SIDA. Pero, ¿por qué este caso fue tan criticado por la comunidad científica? En las siguientes líneas pasamos a explicarlo. 


\section{EL CASO DE LAS NIÑAS INMUNES AL VIRUS DEL VIH NACIDAS EN CHINA BAJO LA TÉCNICA CRISPR}

En agosto del año 2018, He Jiankui, un profesor y científico chino, presentó al público, el caso de las primeras bebés modificadas genéticamente (Lulu y Nana), bajo la técnica de edición de genes conocida como CRISPRCAS9, dos niñas inmunes contra el virus causante del SIDA.

Las niñas fueron concebidas mediante inseminación artificial; luego del proceso de fecundación, el equipo científico inyectó reactivos CRISPR (una especie de tijeras moleculares de precisión), en el embrión, para inactivar el gen CCR $5^{145}$. Sin embargo, ello no es tan sencillo como parece, pues esta proteína cumple con otras funciones en nuestro organismo, la cual nos protege de contraer infecciones que pueden causar enfermedades mortales. El fin era modificar el gen que el virus utiliza como vía para introducirse en el sistema inmunológico humano.

Según el periódico The New York Times (2018), He solo pudo inhabilitar ambas copias del gen CCR5 en una de las gemelas, a quien identificó como Nana. Respecto a la otra gemela, llamada Lulu, solo se logró inhabilitar una copia de dicho gen, lo que proporcionaría una protección limitada contra el VIH.

Pese a que He indicó que las bebés se encontraban en perfecto estado de salud, hasta la fecha no ha publicado la investigación en ninguna revista especializada; cabe señalar que, aparentemente, el experimento no habría resultado tan exitoso como se creía, implicando diversas repercusiones en la vida de las pequeñas Lulu y Nana. Aparte, vale recordar que, las autoridades científicas de Shenzhen, han manifestado que no recibieron una solicitud de permiso para proceder con la modificación llevada a cabo. Por otro lado, la Universidad de Ciencia y Tecnología del Sur, donde se realizó el experimento, no tenía conocimiento de que se estaba realizando, y ha indicado que He Jiankui se encuentra en licencia sin remuneración.

Por lo expuesto, podemos indicar que la aplicación de esta técnica no solo ha sido ilegal, sino también irresponsable, considerando que, pese a las advertencias dadas por diversos científicos, He hizo caso omiso a tales, trayendo como consecuencia que estas gemelas tendrán que ser supervisadas durante toda su vida, pues no se sabe a qué infecciones o enfermedades podrían estar sujetas.

145 El CCR5 puede obrar como correceptor (un segundo sitio de unión a los receptores) del VIH cuando el virus entra a la célula huésped. 
Respecto a ello, Cyranoski citando a Julian Savulescu, en un artículo publicado por la revista Nature, señaló:

Este experimento es monstruoso. Los embriones estaban sanos, sin enfermedades conocidas. La edición genética en sí misma es experimental y todavía está asociada con mutaciones no buscadas, capaces de causar problemas genéticos en etapas tempranas o tardías de la vida, incluido el desarrollo del cáncer". (Cyranoski, 2018, párr. 9) (Traducción nuestra).

Seguido a ello, cabe cuestionarse, ¿acaso no habían otras técnicas para evitar que Lulu y Nana contrajeran el virus del VIH? La comunidad científica en su mayoría opina que no era necesario recurrir a la técnica CRISPR-CAS9.

National Geographic (2019) precisa que no era necesario recurrir a CRISPR- CAS9, debido a que existen otras técnicas muy efectivas, como el diagnóstico genético preimplantacional, para escoger los embriones generados in vitro que estén exentos de la enfermedad que puedan transmitir los padres. En realidad, existen diversas alternativas que son ética y científicamente más recomendables y no suponen un riesgo para la salud de las personas.

Lluis Montoliu, en una charla del año 2017, sobre "Las aplicaciones del CRISPR en biomedicina", dictada en la Cátedra Fundación QUAES UPV (Universidad Politécnica de Valencia), señaló que, si bien la técnica se caracteriza por su efectividad, es susceptible de cometer errores en el sistema, puesto que posee una direccionalidad que permite realizar un corte específico del genoma; sin embargo, alrededor de donde se permite tal corte, se produce una indeterminación. Consecuencia de ello, la limitación es evitar que se produzcan los llamados off target effects (modificaciones en secuencias no deseadas); por ello se debe seguir estudiando esta técnica.

Este caso abre un gran debate ético, sobre todo por la irresponsabilidad de He Jiankui, al realizar un experimento sin medir las consecuencias, y teniendo en cuenta que, al editarse los embriones, el cambio pasará a las siguientes generaciones, creándose una nueva especie de estirpe.

\section{LOS PRIMEROS PASOS}

En el año 2015, salió a la luz que un grupo de investigadores de la Universidad Sun Yat-sen (Guangzhou, China) había editado genéticamente 
embriones humanos, a fin de corregir el defecto genético de la beta talasemia (una enfermedad congénita que afecta la sangre). Este experimento fue llevado a cabo por el científico Junjiu Huang, de la Universidad Sun Yat-Sen, quien con su equipo recurrió a embriones no viables, pues no tenía como intención traer al mundo un bebé; estos embriones fueron obtenidos de una clínica de fertilización in vitro, y no tardaron en ser destruidos.

A diferencia de su compatriota, He Jiankui, el estudio de Huang fue publicado. En un principio, el artículo fue rechazado por las revistas occidentales más prestigiosas, catalogando el experimento como contrario a las normas éticas, y por ofrecer poca ciencia. Sin embargo, meses después, el artículo logró ser publicado en una revista poco conocida, llamada Protein \& Cell, el 18 de Abril del 2015. Según dicho artículo, CRISPR-CAS9 no funcionó de forma exitosa, debido a que en algunos casos generó mutaciones no deseadas, potencialmente dañinas, motivo por el cual se detuvo el experimento.

Asimismo, el científico Huang declaró a la revista Nature: "Si quieres hacerlo en embriones normales, tienes que tener una fiabilidad cercana al $100 \%$ (...) Por eso paramos, creemos que aún es demasiado pronto" (Traducción nuestra).

Años después, en el 2018, una Cumbre sobre la Edición del Genoma, celebrada en Hong Kong; en donde se habló sobre el experimento que llevó a cabo en el 2015, concluyó en su discurso con una fuerte condena a: “cualquier aplicación de edición de genes en embriones humanos con fines reproductivos. Tal intervención es contra la ley, la regulación y la ética médica de China" (Cursiva y traducción nuestra).

\section{EN BÚSQUEDA DE CREAR MÁS BEBÉS MODIFICADOS}

Una de las noticias más actuales respecto al caso, después del escándalo que generó el científico He Jiankui, es la que tiene por protagonista al ruso Dennis Rebrivok quien, según informa la revista Nature, planea crear más bebés modificados genéticamente. Rebrivok explica a la publicación científica británica que pretende usar la potente herramienta de edición genética Crispr-CAS9 para modificar el gen CCR5, exactamente igual como lo desarrolla el científico He Jiankui y con el mismo objetivo, es decir, evitar el contagio por el virus del SIDA de los bebés durante el embarazo (Cyranoski, 2019) (Traducción nuestra).

Sin embargo, a diferencia del científico chino, Rebrivok no piensa actuar a escondidas, sino que ya ha pedido permiso a tres agencias rusas 
para llevar a cabo su experimento; entre ellas, el Ministerio de Salud ruso. De concederle el permiso, Rebrivok pretende implantar los embriones modificados a finales del 2019 y asegura que ya está trabajando con un centro de VIH de Moscú para reclutar a mujeres infectadas por el virus del SIDA que quieran quedar embarazadas.

\section{IV. ¿SE ENCUENTRAN TODOS EN CONTRA DE LOS BEBÉS CRISPR?}

A simple vista, la aplicación de dicha técnica por parte de He, habría sido una decisión muy positiva y valiosa, ya que lo que buscaba era evitar que las menores padecieran de esta enfermedad silenciosa y muy grave como es el SIDA.

Si bien se estaría ayudando a estas menores a que eviten ser portadoras del SIDA, no está tomando en cuenta otras consideraciones científicas, las cuales informan que CRISPR-CAS9, podría producir también un futuro cáncer y otras enfermedades, afectando de esta manera no solo a las menores en el desarrollo físico de su vida, sino también descendencia, porque recordemos que, al aplicar esta técnica, se está haciendo todo un cambio dentro del ADN de una persona, lo cual va a repercutir en las siguientes generaciones.

Al editar una letra del libro de la vida, podemos tener como consecuencia que se alteren páginas enteras en áreas no deseadas. El peligro a largo plazo son los cambios involuntarios en el genoma de un organismo que continúan y pasan a una nueva generación. El riesgo de seguridad es un cambio desconocido en los genes que se transfieren a sus descendientes. Por tal motivo, una de las consecuencias que se especula en los medios, hace referencia a la salud reproductiva y la libertad de las menores; ello debido a que, cuando se acerquen a la edad reproductiva, es posible que se enfrenten a una esterilización forzada, a fin de evitar que sus genes editados se transmitan a otras generaciones, como señala Ball.

De este modo, se están poniendo en juego el derecho a la vida, la integridad y dignidad de las pequeñas, considerando que se ha aplicado una técnica en personas que no tienen autonomía para poder decidir qué es lo que quieren o no quieren para su vida, afectando su integridad, al aplicar una técnica que sabemos que puede generarle complicaciones con el desarrollo físico de su vida.

En la misma línea, Elena Postigo (2019) nos indica que, es una temeridad y una imprudencia contraria a la ética de la investigación aplicar la edición genética en la línea embrionaria y germinal. El principio básico de 
toda bioética es "no hacer daño", y con este tipo de intervenciones podría dañarse seriamente la vida de las personas.

En la actualidad, el futuro de estas menores es totalmente especulativo e incierto, ya que estas niñas estarán siendo supervisadas durante toda su vida, debido a que esta técnica puede traer una serie de mutaciones involuntarias, además de enfermedades infecciosas, o incluso la preocupación durante toda su vida de desarrollar un cáncer.

\section{ABRIENDO LAS PUERTAS A UNA POSIBLE EUGENESIA}

Una de las críticas más frecuentes a la técnica es que la posibilidad de editar la línea germinal humana, abre las puertas a una posible eugenesia, pues cabe la posibilidad de seleccionar seres humanos, introduciendo características perfeccionadas, creando de esta forma una nueva clase de estirpe, y reduciendo al ser humano a un mero producto del mercado.

En esta línea, Lluis Montoliu, en una entrevista con el diario El País, sostiene:

Se ha abierto una caja de pandora. Es de una irresponsabilidad colosal. No es una edición para curar. Es una mejora genética. El paso siguiente es una eugenesia total. Le dirán a los padres: “Qué desea usted?", pudiendo darse que en unos 20 o 30 años, las niñas desarrollen una enfermedad autoinmune, en la que las defensas de su organismo ataquen a sus propias células, cambios que pasarán a sus hijos al haberse alterado su ADN, creándose una nueva estirpe de humanos. (Montoliu, 2018)

Emmanuelle Charpentier, una de las inventoras de la edición genética, señala que, no es partidaria de usar esta técnica para crear humanos transformados o mejorados, pues debemos ser cautos incluso al aplicar esta nueva técnica en embriones para curar enfermedades.

Lo cierto es que lo que en el pasado parecía una cuestión técnica, hoy en día es muy probable que se pueda cumplir, y habría que preguntarnos cómo se encuentra actualmente nuestra sociedad para hacer frente ante estos avances, si es que los padres/consumidores querrían usar la modificación de la línea germinal para practicar una mejora en sus hijos.

Peter Singer (2002) afirma que si partimos de la asunción optimista de que los padres seleccionarán sólo los genes que sean beneficiosos para sus 
hijos, al menos existen tres ámbitos diferentes, en donde se pueda pensar que ello pudiera tener consecuencias sociales adversas:

- La primera, hace referencia a que los rasgos que se busca asegurar para los hijos serían beneficiosos solo en términos comparativos y no absolutos.

- La segunda, hace referencia al temor del hecho que supondría una menor diversidad entre los seres humanos, considerando que no todas las formas de diversidad son buenas.

- La tercera, y más importante, refiere a la amenaza contra el ideal de igualdad de oportunidades. Así, las desigualdades económicas se volverán desigualdades genéticas y el reloj se retrasará siglos en la lucha para superar los privilegios de la aristocracia. En lugar de ello, la generación presente de gente rica tendrá la oportunidad de incorporar sus ventajas a los genes de sus descendientes.

\section{PROBLEMAS EN EL PARAÍSO GENÓMICO}

Ante el polémico caso de las primeras bebes modificadas genéticamente, la revista Nature en su edición de junio del 2019, publicó un artículo en el que daba cuenta que estas hermanas podrían morir con anterioridad, es decir, antes que las gemelas cumplan un ciclo de vida normal o común del ser humano, debido a que el científico que editó los genomas de las gemelas, en un intento de hacerlas resistentes al VIH, podría haber reducido inadvertidamente su esperanza de vida.

Alejandra Martins (2018), en una publicación de BBC News precisa las siguientes desventajas y problemas que produce la aplicación de la técnica de edición genética CRISPR CAS9:

- Se podrán manipular los embriones al antojo del cliente (padres), ya que al ser una técnica accesible para todos, las personas comenzarán a hacer mal uso de CRISPR, para que de esta manera los progenitores manipulen a los embriones y los "fabriquen" según sus gustos, creando de esta manera los llamados "bebés a la carta".

- Se crearán nuevas formas de discriminación, ya que se dará la selección de embriones, desechando o congelando a los demás, tratándolos como simples objetos.

- Esta nueva técnica podría producir cáncer. 
- Además recordemos que, dado que esta técnica funciona como unas tijeras que cortan y pegan el ADN, en el lapso de ese proceso, el ADN querrá unirse nuevamente, generando de esta manera una nueva escalera genética, la cual puede traer consecuencias en el futuro, con diversas enfermedades para la persona misma o para su descendencia.

- Por otro lado, tras la desactivación del gen CCR5, las personas podrían contraer muy rápidamente el virus de la gripe e infecciones que pueden llegar a ser mortales.

\section{CRISPR-CAS9 Y LA BATALLA ÉTICA}

Recordemos que la bioética es una disciplina reciente, cuya finalidad y preocupación primordial es proteger la integridad y la dignidad del ser humano frente al desarrollo tecnológico, que cada vez se hace presente con más fuerza en nuestra sociedad.

Debemos estar de acuerdo con los avances tecnológicos y médicos, pero estos deben ser aplicados con prudencia, responsabilidad y siguiendo lineamiento éticos y legales. Lamentablemente, hoy en día el ser humano ha dejado de preguntarse el porqué de cada decisión o cada acto que realizamos, por lo que este abandono respecto a lo que sucede en nuestro alrededor nos ha llevado a vivir en un mundo donde el egoísmo y la indiferencia imperan, y son vistos como actos totalmente normales.

Como dice Julián Marías:

"Vivimos una renuncia a entender, el hombre ha dejado de hacerse preguntas, asumiendo entonces una actitud en que no se ve como persona responsable, con dudas, problemas, fines, deberes". (Marías, s.f)

El problema no es entonces la aparición de esta nueva técnica de edición genética (CRISPR), sino que es el mismo hombre, quien sin estudiar suficientemente, ni cuestionarse las consecuencias que conllevan aplicar esta técnica, ha optado por aplicarla a seres humanos, dando por hecho que va a tener siempre consecuencias positivas y que va a servir para protegernos de enfermedades. Sin embargo, como ya se mencionó, esta técnica es todavía nueva, no existiendo aun la suficiente experiencia, ni los estudios necesarios como para afirmar que es totalmente aceptable y positiva para su aplicación en humanos. 


\section{PRINCIPIOS BIOÉTICOS}

El principio fundamental o la base de la bioética, es el respeto a la vida, la que debe ser salvaguardada. Respecto al caso de las menores editadas genéticamente, debido a la llegada de CRISPR, cabe tomar en cuenta, además los siguientes principios.

\section{a) Principio de Precaución}

El acuerdo con la UNESCO, “Cuando las actividades humanas pueden acarrear un daño moralmente inaceptable que es científicamente plausible pero incierto, se adoptarán medidas para evitar o disminuir ese daño."

Este principio hace referencia a que, cuando se da el visto bueno ético a una nueva práctica biomédica, no solamente se debe valorar lo que pueda derivarse directamente de esa experiencia en concreto, sino las consecuencias que a largo plazo puedan darse.

Como bien se menciona, es necesario tener en cuenta las consecuencias que pueden generarse en un futuro para el ser humano, si aceptamos diversas técnicas experimentales y clínicas; es por ello que las medidas expuestas en líneas anteriores deben ser estudiadas correcta y minuciosamente ante la aparición de cualquier proyecto científico-clínico sobre la materia, para que realmente el principio de precaución funcione de la manera correcta, y logre su finalidad, que es la preservación de la vida humana.

Por ello, debe ahondarse en estudios para conocer los pro y contras que implica utilizar esta técnica, y la manera en cómo se puede afectar a la persona y las futuras generaciones.

\section{b) Principio de Autotelia}

Uno de los principios fundamentales del pensamiento moderno es el "Principio de Autotelia"; de acuerdo a la línea Kantiana: "Todo hombre es un fin en sí mismo".

Según Miró Quesada Cantuarias, quien sigue la línea Kantiana, en el año 1966 sentó las bases para la construcción de una política humanista, en donde precisó lo siguiente: "El principio de autotelia es suficiente fundamento para que el humanismo quede constituido. Todos los demás principios se pueden deducir de él por medio de la lógica y del análisis semántico". (Miro Quesada, 1966) 
Si el hombre es un fin en sí mismo según Kant, jamás debe ser utilizado como un medio. Sin embargo, esto fue lo que sucedió en el caso de las menores Lulu y Nana, quienes fueron sometidas a la aplicación de la técnica CRISPR, siendo un experimento nuevo, y en donde no se midió las consecuencias que se podían generar en agravio de las menores. Lamentablemente, hoy en día son las menores quienes sufrirán las consecuencias de CRISPR; es evidente que fueron utilizadas como un medio para comprobar la efectividad de un nuevo experimento, en donde se creía que, utilizándolo, se podría evitar cualquier enfermedad; viéndose totalmente vulnerado este principio ético.

Cabe mencionar, el oportunismo que se ha visto expuesto por el científico chino He Jiankui, quien evidentemente utilizó a las menores para darse a conocer en el mundo de la ciencia, utilizándolas como ya lo mencionamos, como un simple medio, para que finalmente obtenga un reconocimiento en el campo científico. El principio de autotelia protege al ser humano y a su integridad, desafortunadamente en este caso, tal principio se ha visto violentado por la inconciencia y el deshumanismo de muchas personas, al no prever las consecuencias de la aplicación de una nueva técnica científica, tal como lo ha realizado el científico He Jiankui.

\section{c) Principio de Beneficiencia}

Según Tom L. Beauchamp y James F. Childress (1979) puede definirse el principio de beneficencia de la siguiente manera:

Se refiere a la obligación moral de actuar en beneficio de otros. Muchos actos de beneficencia son obligatorios, pero un principio de beneficencia, tal y como nosotros lo entendemos, impone una obligación de ayudar a otros a promover sus importantes y legítimos intereses.(p.166)

Tal como se menciona al inicio, el principio de beneficencia lo que busca es beneficiar a otras personas y ayudar a promover sus intereses. Trabajando desde esta perspectiva, podríamos ponernos en el supuesto de que el científico He Jiankui, trató de ayudar a los padres de Lulu y Nana, aplicando la técnica CRISPR, para evitar que sus menores hijas desarrollen el virus del SIDA.

Sin embargo, planteando esta posición en la realidad y actualidad, gracias a todos los estudios realizados, podemos precisar que el principio de beneficencia se ha visto vulnerado, debido a que la técnica CRISPR, como bien hemos mencionado, genera una serie de enfermedades que causan daños de por vida en la vida del ser humano, ahora cabe la pregunta ¿Realmente se respetó el principio de beneficencia frente a las gemelas Lulu y Nana? 
Es evidente que la respuesta ante esta interrogante, es un rotundo no, pues las gemelas tendrían un tiempo estimado de vida menor a la de cualquier otra persona, debido a que la aplicación de CRISPR, consiste en inactivar el gen CCR5, lo que producirá en las gemelas una serie de enfermedades infecciosas, además de negarles la oportunidad de conformar su propia familia, ya que probablemente la pesadilla de esta técnica CRISPR, les genere una esterilización prematura, para que estas modificaciones genéticas no repercutan en futuras generaciones. Queda claro entonces que, el principio de beneficencia no ha sido tomado en cuenta frente a este caso.

\section{CONCLUSIÓN}

Si bien CRISPR nos abre la puerta a miles de oportunidades, debemos tener en cuenta que este tipo de técnicas deben ser aplicadas con prudencia, pues el avance científico debe ir de la mano con fundamentos éticos. De este modo, consideramos que el derecho no puede ser ajeno a estos avances, y por ello resulta necesario sentar bases legales estableciendo los límites, y tratando de dar salidas al avance científico, siempre que se respete la vida humana. Recordemos que, las leyes para ser verdaderas, deben estar fundadas en valores morales.

El ser humano realiza un gran esfuerzo por querer mejorarlo todo, incluso sus propios genes. Sin embargo, si analizamos el estado de nuestra sociedad actual podemos percatarnos que muchos descubrimientos amenazan al propio ser humano; ya que al buscarse el perfeccionamiento del mismo, lo reduce a un mero producto, dejando que sea víctima de la comercialización y el consumismo. Además, con la llegada de estas nuevas técnicas el porcentaje de discriminación se ve altamente elevado, al buscar un ser humano "mejor" o "perfecto", para satisfacer necesidades ajenas.

Finalmente, es necesario preocuparse sobre lo que esta nueva sociedad está generando, y es que cada vez más, podemos apreciar la cosificación del ser humano, al ser tratados como simples objetos, productos que pueden ser manipulados al antojo de la persona. Reflexionemos frente a esta nueva situación, y recordemos que el ser humano no puede jugar a ser Dios y alterar la naturaleza, manipulándola como mejor le parezca, haciendo un uso irresponsable de la técnica CRISPR CAS9.

\section{REFERENCIAS}

Ansede, M. (2018). Han creado una estirpe nueva de humanos. El País. Recuperado de: https://elpais.com/elpais/2018/11/26/ 
ciencia/1543253567_659329.html

Ball, P. (2018). World's first gene-edited babies created in China, claims scientist. The Guardian. Recuperado de: https://www.theguardian. com/science / 2018/nov/26/worlds-first-gene-edited-babiescreated-in-china-claims-scientist

Cyranoski, D. y Ledford, H. (2018). Genome-edited baby claim provokes international outcry. Nature. Recuperado de: https://www.nature. com/articles/d41586-018-07545-0

Cyranoski, D. y Reardon, S. (2015). Chinese scientists genetically modify human embryos. Nature. Recuperado de: https://www.nature. $\mathrm{com} /$ news/chinese-scientists-genetically-modify-human-embryos1.17378?WT.mc_id=TWT_NatureNews\#/b2

Domínguez, N. (2018). Emmanuelle Charpentier: No debemos usar la edición genéticaparacrearhumanosmejorados.ElPaís.Recuperadode:https: / / elpais.com/elpais/2018/10/01/ciencia/1538376843_872476.html

Kirksey, E. (2018). Even china roundly condemns editing the genes of babies. Wired. Recuperado de: https://www.wired.com/story/even-chinaroundly-condemns-editing-the-genes-of-babies /

Kolata, G. y Belluck, P. (2019). ¿Por qué los científicos están tan molestos con los primeros bebés Crispr? The New York Times ES. Recuperado de: https://www.nytimes.com/es/2018/12/07/primeros-bebesgeneticamente-editados/

Lluis Montoliu (2017). Charla del Dr. Lluis Montoliu sobre las aplicaciones del CRISPR en biomedicina. [Youtube]. Recuperado de: https://www. youtube.com/watch?v=mFKIHFKEoIg

Marías, J. (s.f). La razón en la filosofía actual. Recuperado de http:www.filosofia. orglaut/003/m49a0936.pdf

Martins A. (2018). CRISPR/Cas9: las serias advertencias de unos científicos sobre los peligros de la técnica que revolucionó la genética. $B B C$ News Mundo. Recuperado de: https://www.bbc.com/mundo/ noticias-44861150

Postigo, E. (2019). Las bebes chinas nacidas con CRISPR. [Facebook]. 
Recuperado de https://www.facebook.com/elena.postigo.solana/ posts/10158531673454606

UNESCO. (2005). Informe del Grupo de Expertos sobre el principio precautorio. Recuperado de https://unesdoc.unesco.org/ark:/48223/pf0000139578_ spa

Universitat Ramon LLull, Càtedra Ethos. Principios de la Bioética. Recuperado de: https://www.bioeticaweb.com/autonomasa-y-beneficiencia-dosprincipios-en-tensiasn/

Reardon, S. (2019). Gene edits to 'CRISPR babies' might have shortened their life expectancy. Nature. Recuperado de: https://www.nature.com/ articles / d41586-019-01739-w

Singer, P. (2002). De compras por el supermercado genético. Princeton University. Traducción de Julio Seonane. Recuperado de: http://www.acuedi. org/ddata/10906.pdf

Torres, L. (2019). Cómo ha cambiado CRISPR la edición genética. National Geographic España. Recuperado de: https:/ /www.nationalgeographic. com.es/ciencia/actualidad/la-tecnologia-crispr-ha-democratizadoedicion-genetica_13940

Fecha de recepción: 28 de octubre de 2019

Fecha de aceptación: 14 de noviembre de 2019 